\title{
Predictive factors of overall and major postoperative complications after partial nephrectomy: Results from a multicenter prospective study (The RECORd 1 project)
}

\author{
A. Mari ${ }^{\mathrm{a}}$, A. Antonelli ${ }^{\mathrm{b}}, \mathrm{R}_{\text {. Bertolo }}{ }^{\mathrm{C}}, \mathrm{G}$. Bianchi ${ }^{\mathrm{d}}$, M. Borghesi ${ }^{\mathrm{e}}$, \\ V. Ficarra ${ }^{f}$, C. Fiori ${ }^{\mathrm{c}}$, M. Furlan ${ }^{\mathrm{b}}$, S. Giancane ${ }^{\mathrm{a}}$, N. Longo ${ }^{\mathrm{g}}$,

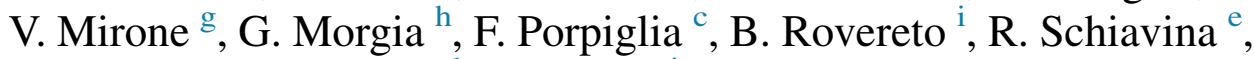 \\ S. Serni ${ }^{a}$, C. Simeone ${ }^{b}$, A. Volpe ${ }^{j}$, M. Carini ${ }^{a}$, A. Minervini ${ }^{a}{ }^{a}$

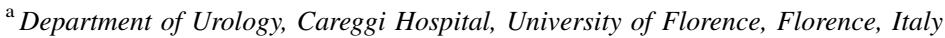 \\ ${ }^{\mathrm{b}}$ Department of Urology, AO Spedali Civili di Brescia, Brescia, Italy \\ ${ }^{\mathrm{c}}$ Department of Urology, San Luigi Gonzaga Hospital, Orbassano, Turin, Italy \\ ${ }^{\mathrm{d}}$ Department of Urology, Policlinico di Modena, University of Modena, Modena, Italy \\ ${ }^{\mathrm{e}}$ Department of Urology, University of Bologna, S. Orsola Malpighi Hospital, Bologna, Italy \\ ${ }^{\mathrm{f}}$ Department of Urology, University of Padua, Padua, Italy \\ ${ }^{\mathrm{g}}$ Department of Urology, Policlinico Federico II, University of Naples, Naples, Italy \\ ${ }^{\mathrm{h}}$ Luna Foundation, Italy \\ ${ }^{\mathrm{i}}$ Department of Urology, I.R.C.C.S. Policlinico San Matteo, Pavia, Italy \\ ${ }^{\mathrm{j}}$ Department of Urology, Maggiore della Carità Hospital, Novara, Italy
}

Accepted 14 October 2016

Available online 5 November 2016

\begin{abstract}
Introduction and objectives: To analyze postoperative complications and to assess for significant predictive factors during partial nephrectomy (PN) using a large multicenter dataset.

Methods: Patients who underwent PN for clinical T1 renal tumors at 19 urological Italian centers (Registry of Conservative Renal Surgery [RECORd] project) were evaluated between 2009 and 2012. Anthropometric data, comorbidities and perioperative outcomes were analyzed. Complications were divided as intra- and postoperative, medical and surgical, as appropriate. The severity of postoperative complications was graded according to the modified Clavien classification system. Patients who experienced intraoperative complications were excluded from the analyses for the potential confounding effect in the evaluation of predicting factors for postoperative complications.

Results: Overall, 979 patients were analyzed: open, laparoscopic and robot-assisted (available since 2011) surgical approaches were used in 522 (56.4\%), 286 (30.9\%) and 117 (12.6\%) cases, respectively. Surgical postoperative complications were reported in $121(13.1 \%)$ cases (32 (3.5\%) were Clavien 3), medical were reported in $52(5.6 \%)$ cases (3 (0.3\%) were Clavien 3). No Clavien 4 complications were reported. At multivariable analysis, ECOG score $\geq 1$ (OR 1.98; $\mathrm{p}=0.002)$, lower preoperative hemoglobin (OR 0.71; $\mathrm{p}<0.0001)$ and open surgical approach (2.91; $\mathrm{p}=0.02)$ were significant predictive factors of overall surgical postoperative complications, ECOG score $\geq 1(\mathrm{OR} 1.93 ; \mathrm{p}=0.04)$ and surgical approach $(\mathrm{p}=0.05)$ were significant predictive factors of Clavien 3 either surgical or medical postoperative complications.

Conclusions: Comorbidities and surgical approach should be considered in preoperative evaluation of patients undergoing PN, as they resulted to play a significant role in the occurrence of postoperative complications.

(C) 2016 Elsevier Ltd, BASO The Association for Cancer Surgery, and the European Society of Surgical Oncology. All rights reserved.
\end{abstract}

Keywords: Renal cell carcinoma; Partial nephrectomy; Open partial nephrectomy; Laparoscopy; Robotics; Robot-assisted partial nephrectomy; Nephronsparing surgery

\footnotetext{
* Corresponding author. Department of Urology, University of Florence,

Careggi Hospital, Florence, Italy. Tel.: +39 0552758011.

E-mail address: andreamine@libero.it (A. Minervini).
} 


\section{Introduction}

Renal cell carcinoma (RCC) diagnosis has increased worldwide in both men and women because of higher use of diagnostic imaging.

Historically, partial nephrectomy (PN) was exclusive for small renal masses or patients with reduced renal function, but with advances of surgical skills, its indications have broaden out to high-complex tumors such as hilar, completely endophytic and clinical T1b renal masses. ${ }^{2,3}$ PN has been associated, in observational and retrospective studies, with reduced mortality for cardiovascular accidents compared to radical nephrectomy. Concurrently, postoperative surgical complications represent the prominent concern of PN, as they have been reported in up to $30 \%$ of cases, with a major (Clavien 3-4) complication rate of 3-6\%.

Hemorrhagic complications caused by bleeding from the healthy renal parenchyma represent common and potentially life-threatening events, as they may require blood transfusions and, in some cases, a radiologic maneuver or a surgical reintervention. Urinary fistulas are often associated to the resection of endophytic renal masses, as a consequence of a renal calyceal violation. Usually, they are managed by a prolonged maintenance of abdominal drain and, as second line of treatment, by ureteral stenting. ${ }^{5,6}$

Multiple factors have been variously reported as predictive of surgical complications. These factors seem to be dependent on patients' clinical characteristics, nephrometry parameters, surgical approach and technique. ${ }^{3,7}$

The aim of this study is to analyze postoperative complications of $\mathrm{PN}$ and to assess for significant predictive factors in $\mathrm{T} 1$ renal tumors by the retrospective analysis of a prospective multicentre cohort (RECORd1 Project).

\section{Materials and methods}

The Italian Registry of Conservative Renal Surgery (RECORd Project) is a 4-year prospective observational multicentre study promoted by the Leading Urological No profit foundation Advanced research (LUNA) of the Società Italiana di Urologia (SIU). The RECORd project includes all patients who underwent conservative surgical treatment for radiologically diagnosed renal cell carcinoma (RCC) between January 2009 and December 2012 at 19 urological Italian Centers, upon the approval of the study protocol by the local ethical committee and patients' acceptance of the written informed consent. ${ }^{8}$

An online central data server was generated. It contains anthropometric, preoperative, and imaging data, indications and comorbidities, intra and post-operative data, histopathological analysis. All data were prospectively recorded by medical doctors. Surgical indications were defined as elective (localized unilateral RCC with healthy contralateral kidney), relative (localized unilateral RCC with the coexistence of comorbidities such as diabetes, hypertension or lithiasis that could potentially affect kidney function in the future) and absolute (bilateral tumors, multiple tumors, moderate to severe CKD or tumors involving an anatomically or functionally solitary kidney).

Patients with uncontrolled diabetes at preoperative exams were submitted either to the Diabetes center of the referring hospital or the anesthesiologist in charge and had their treatment changed to achieve a better control of glycemia. Similarly, patients with uncontrolled hypertension had their treatment changed either by cardiologist or anesthesiologist in charge.

Performance status was assigned according to the ECOG criteria. ${ }^{9}$ In all patients, clinical workup included at least abdominal computed tomography (CT) scan and chest Xray. Tumors were classified according to their location on the longitudinal plane (upper pole, middle part, and lower pole) and on the transverse plane (anterior surface, posterior surface, lateral margin, medial margin, peri-hilar) of the kidney. According to the degree of depth into the kidney, each tumor was also classified into three growth pattern categories: prevalently $(\geq 50 \%)$ exophytic, prevalently endophytic ( $<50 \%$ exophytic), and entirely endophytic. Centers were divided in low- and high-volume according to the threshold of 50 PNs performed per year. All intraoperative data including surgical approach and technique, the decision whether to clamp the renal vessels, type of ischemia, warm ischemia time (WIT), intraoperative estimated blood loss (EBL) and operative time were recorded. The minimally invasive, laparoscopic or robot assisted, and open approaches as well as the surgical technique, performed in the form of standard PN or simple enucleation (SE), were adopted according to the centers' and surgeons' preference. Robot-assisted and laparoscopic approaches were routinely done in 5 and 11 over 19 centers, respectively. Surgeons were all skilled in performing either robot-assisted, laparoscopic or open PN. Standard PN has been defined as the excision of the tumor with a minimal margin of healthy peritumoral renal parenchyma. SE has been defined as the blunt tumor excision without removing a visible rim of parenchymal tissue around the pseudocapsule. ${ }^{10}$ Hemoglobin, hematocrit, creatinine, and estimated glomerular filtration rate (eGFR) by using modification of diet in renal disease (MDRD) formula were recorded for each patient preoperatively, in the first day and within the first month postoperatively. Intraoperative complications were defined as medical and/or surgical complications occurring between induction of the anesthesia and patient awakening that could potentially cause injury and require unplanned medical or surgical maneuvers. Hospital stay and postoperative complications occurring within 30 days from surgery were recorded. Surgical postoperative complications were defined as any postoperative event caused by surgery until the $30^{\text {th }}$ postoperative day (POD), altering the normal postoperative course and/or delaying discharge. Medical postoperative complications were defined as any postoperative event with no direct relation to surgery until the 30th POD, altering the normal postoperative course 
and/or delaying discharge. The severity of complications was graded according to the modified Clavien classification system. ${ }^{6}$ The ten Martin's criteria for accurate and comprehensive reporting of surgical complications ${ }^{11}$ and the European Association of Urology (EAU) standardized quality criteria on reporting PN surgical complications were applied. $^{12}$

For the purpose of the study, only patients with clinical $\mathrm{T} 1$ ( $\leq 7 \mathrm{~cm}$ diameter at radiological diagnosis) renal tumors were included. Furthermore, patients who experienced intraoperative complications were excluded from the data analyses for their potential confounding effect in the evaluation of preoperative and intraoperative risk factors for postoperative complications.

Categorical variables were reported as frequencies and proportions. Continuous variables were considered parametric or not parametric basing on kurtosis and skewness values and, therefore, reported as mean and standard deviation (SD) or as median and interquartile range (IQR), as appropriate. The Student $t$ test and the Mann-Whitney U test were used to compare continuous to categorical variables and the Pearson's chi square test was used to compare two categorical variables. A logistic regression was used to make multivariable analyses. Statistical significance was set as $\mathrm{p} \leq 0.05$. All reported $\mathrm{p}$ values were two-sided. Analyses were carried out with SPSS version 20.0 (SPSS Inc, Chicago, IL, USA).

\section{Results}

Overall, 979 patients were included in the dataset. For the purpose of the study, 14 cases of clinical T2 renal tumors, as well as 40 cases who experienced intraoperative complications were excluded. Preoperative features of 925 patients are summarized in Table 1. Overall, 676 (73.1\%) patients were treated in high volume centers, median body mass index (BMI) was 26.0 (IQR 24.1-28.4) $\mathrm{kg} / \mathrm{m}^{2}$, ECOG score was $\geq 1$ in $288(31.1 \%)$ cases. Surgical indication was elective in $736(79.6 \%)$ patients, relative in $127(13.7 \%)$ and absolute in $62(6.7 \%)$. Mean clinical tumor diameter was 3.2 (SD 1.3) cm and 185 (20.0\%) cases were clinical $\mathrm{T} 1 \mathrm{~b}$.

Surgical and postoperative features are summarized in Table 2. Open PN (OPN) was performed in 522 (56.4\%) cases, laparoscopic (LPN) in $286(30.9 \%)$ cases and robot-assisted (RAPN), available since 2011, in 117 (12.6\%) cases. SE technique was performed in 374 (40.4\%) cases and standard PN technique in 551 (59.6\%) cases. Surgical postoperative complications were reported in $121(13.1 \%)$ cases: $78(8.4 \%)$ hemorrhages treated by transfusions (Clavien 2), $4(0.4 \%)$ treated by superselective embolization $(\mathrm{Cl} 3), 10(1.0 \%)$ by surgical reinterventions for bleeding (Clavien 3), 5 (0.5\%) urinary fistulas managed by drain manipulation (Clavien 1$)$ and $20(2.1 \%)$ treated by stenting (Clavien 3), 5 (0.5\%) acute renal failures caused by prolonged WIT (Clavien 1), 1 (0.1\%) pneumothorax treated
Table 1

Descriptive analysis of preoperative features.

\begin{tabular}{|c|c|c|c|}
\hline \multicolumn{4}{|l|}{ Preoperative features } \\
\hline \multirow[t]{2}{*}{ Center volume, n. \% } & High & 676 & $73.1 \%$ \\
\hline & Low & 249 & $26.9 \%$ \\
\hline \multirow[t]{2}{*}{ Gender, n. \% } & Male & 600 & $64.9 \%$ \\
\hline & Female & 325 & $35.1 \%$ \\
\hline \multicolumn{2}{|l|}{ Age (yrs), mean SD } & 62.0 & 12.6 \\
\hline \multicolumn{2}{|l|}{ BMI $\left(\mathrm{kg} / \mathrm{m}^{2}\right)$, median IQR } & 26.0 & $24.1-28.4$ \\
\hline \multirow[t]{2}{*}{ Uncontrolled diabetes, n. (\%) } & No & 885 & $95,7 \%$ \\
\hline & Yes & 40 & $4,3 \%$ \\
\hline \multirow{2}{*}{$\begin{array}{l}\text { Uncontrolled hypertension, } \\
\text { n. }(\%)\end{array}$} & No & 808 & $87,4 \%$ \\
\hline & Yes & 117 & $12,6 \%$ \\
\hline \multirow[t]{2}{*}{ ECOG, n. \% } & 0 & 637 & $68.9 \%$ \\
\hline & $\geq 1$ & 288 & $31.1 \%$ \\
\hline \multirow[t]{3}{*}{ Indication, n. \% } & Elective & 736 & $79.6 \%$ \\
\hline & Relative & 127 & $13.7 \%$ \\
\hline & Absolute & 62 & $6.7 \%$ \\
\hline \multirow{2}{*}{ Tumor side, n. $\%$} & Right & 492 & $53.2 \%$ \\
\hline & Left & 433 & $46.8 \%$ \\
\hline \multicolumn{2}{|l|}{ Clinical diameter, mean SD $(\mathrm{cm})$} & 3.2 & 1.3 \\
\hline \multicolumn{2}{|c|}{ Clinical diameter, median IQR $(\mathrm{cm})$} & 3.0 & $2.0-4.0$ \\
\hline \multirow{2}{*}{ Clinical T, n. \% } & T1a & 740 & $80.0 \%$ \\
\hline & T1b & 185 & $20.0 \%$ \\
\hline \multirow[t]{3}{*}{ Tumor site, n. \% } & Polar sup. & 261 & $28.2 \%$ \\
\hline & Mesorenal & 375 & $40.5 \%$ \\
\hline & Polar inf. & 289 & $31.2 \%$ \\
\hline \multirow[t]{3}{*}{ Tumor growth pattern, n. $\%$} & $\geq 50 \%$ Exophytic & 692 & $74.8 \%$ \\
\hline & $<50 \%$ Exophytic & 207 & $22.4 \%$ \\
\hline & Entirely endophytic & 26 & $2.8 \%$ \\
\hline \multirow[t]{5}{*}{ Tumor localization, n. \% } & Peri-hilar & 49 & $5.2 \%$ \\
\hline & Anterior face & 270 & $29.1 \%$ \\
\hline & Posterior face & 257 & $27.7 \%$ \\
\hline & Medial margin & 81 & $8.6 \%$ \\
\hline & Lateral margin & 268 & $28.9 \%$ \\
\hline \multirow[t]{2}{*}{ Multiple lesions, n. \% } & No & 879 & $95.0 \%$ \\
\hline & Yes & 46 & $5.0 \%$ \\
\hline \multicolumn{2}{|c|}{ Preoperative hemoglobin $(\mathrm{mg} / \mathrm{dl})$, mean SD } & 14.1 & 1.4 \\
\hline \multicolumn{2}{|c|}{ Preoperative eGFR $\left(\mathrm{ml} / \mathrm{min} / 1.73 \mathrm{~m}^{2}\right)$, median IQR } & 82.3 & $69.7-97$ \\
\hline
\end{tabular}

with pleural drainage (Clavien 3)and $1(0.1 \%)$ bowel subocclusion (Clavien 1). Overall, 75 (8.1\%) surgical postoperative complications were Clavien 2 and 32 (3.5\%) were Clavien 3. No surgical Clavien 4-5 grade complications were recorded. Medical postoperative complications were reported in $52(5.6 \%)$ cases. Clavien 1-2 medical complications $(5.3 \%)$ were respiratory in 26 cases $(2.7 \%)$ (16 pneumonias, 4 acute respiratory distress syndromes, 5 pleural effusions, 1 pulmonary hypertension), cardiologic in $18(1.8 \%)$ cases (5 ischemic events, 11 arrhythmias, 2 hypertensive crisis), one deep venous thrombosis $(0.1 \%)$ and from other causes in $7(0.7 \%)$ patients. All three Clavien 3 medical complications $(0.3 \%)$ were respiratory: 2 pneumothoraxes treated by pleural drainage and 1 acute respiratory distress syndrome treated by tracheal intubation. Positive surgical margins were reported in $41(5.5 \%)$ over 740 malignant tumors.

We assessed pre- and intra-operative variables related to overall and Clavien 3 surgical postoperative complications (Tables 3 and 4). At univariate analysis uncontrolled 
Table 2

Descriptive analysis of surgical postoperative and histological features.

\begin{tabular}{|c|c|c|c|}
\hline \multicolumn{4}{|l|}{ Surgical and postoperative features } \\
\hline \multirow[t]{3}{*}{ Approach, n. \% } & Open & 522 & $56.4 \%$ \\
\hline & VLP & 286 & $30.9 \%$ \\
\hline & Robot & 117 & $12.6 \%$ \\
\hline \multirow[t]{2}{*}{ Technique, n. \% } & Simple enucleation & 374 & $40.4 \%$ \\
\hline & Standard PN & 551 & $59.6 \%$ \\
\hline \multirow[t]{2}{*}{ Hilar clamping, n. \% } & Not performed & 335 & $36.2 \%$ \\
\hline & Performed & 590 & $63.8 \%$ \\
\hline \multicolumn{2}{|l|}{ Ischemia time $(\min )$, median IQR } & 16.0 & $12.0-20.0$ \\
\hline \multicolumn{2}{|l|}{ EBL (cc), median IQR } & 150 & $100-250$ \\
\hline \multicolumn{2}{|l|}{ Operative time (min), median IQR } & 130 & $105-170$ \\
\hline \multicolumn{2}{|l|}{ Length of stay (days), median (IQR) } & 6.0 & $4.0-7.0$ \\
\hline \multicolumn{2}{|l|}{ Preop-1st day $\Delta$ hemoglobin (mg/dl), mean SD } & 2.0 & 1.4 \\
\hline \multicolumn{2}{|l|}{ Preop-3rd day $\Delta$ hemoglobin $(\mathrm{mg} / \mathrm{dl})$, mean SD } & 2.7 & 1.5 \\
\hline \multicolumn{2}{|l|}{ Preop-3rd day $\Delta$ eGFR, median (IQR) } & 10.2 & $0-23.6$ \\
\hline \multicolumn{2}{|l|}{ Preop-30th day $\Delta$ eGFR, median (IQR) } & 8.9 & $0-21.4$ \\
\hline \multicolumn{2}{|l|}{ Surgical complications, n (\%) } & 121 & $13.1 \%$ \\
\hline \multicolumn{2}{|l|}{ - Transfusions, n. \% } & 78 & $8.4 \%$ \\
\hline \multicolumn{2}{|l|}{ - Superselective embolization, n. \% } & 4 & $0.4 \%$ \\
\hline \multicolumn{2}{|l|}{ - Surgical reintervention (bleeding), n. \% } & 10 & $1.0 \%$ \\
\hline \multicolumn{2}{|l|}{ - Urinary fistula treated without stenting, n. \% } & 5 & $0.5 \%$ \\
\hline \multicolumn{2}{|l|}{ - Urinary fistula treated with stenting, n. \% } & 20 & $2.1 \%$ \\
\hline \multicolumn{2}{|l|}{ - Acute renal failure, n. \% } & 5 & $0.5 \%$ \\
\hline \multicolumn{2}{|l|}{ - Pneumothorax treated with drainage, n. \% } & 1 & $0.1 \%$ \\
\hline \multicolumn{2}{|l|}{ - Intestinal subocclusion, n. \% } & 1 & $0.1 \%$ \\
\hline \multicolumn{2}{|l|}{ Surgical Clavien 2, n. \% } & 86 & $9.3 \%$ \\
\hline \multicolumn{2}{|l|}{ Surgical Clavien 3, n. $\%$} & 34 & $3.5 \%$ \\
\hline \multicolumn{2}{|l|}{ Medical complications, n (\%) } & 52 & $5.6 \%$ \\
\hline \multicolumn{2}{|l|}{ - Respiratory complications, n. \% } & 29 & $3.2 \%$ \\
\hline \multicolumn{2}{|l|}{ - Cardiologic complications, n. \% } & 18 & $1.9 \%$ \\
\hline \multicolumn{2}{|l|}{ - Deep venous thrombosis, n. \% } & 1 & $0.1 \%$ \\
\hline \multicolumn{2}{|l|}{ - Others medical complications, n. \% } & 7 & $0.7 \%$ \\
\hline \multirow[t]{2}{*}{ Surgical margins, $\mathrm{n}$ (\% in malignant tumors) } & Negative & 699 & $94.5 \%$ \\
\hline & Positive & 41 & $5.5 \%$ \\
\hline
\end{tabular}

diabetes, ECOG score $\geq 1$, relative and absolute surgical indication, clinical diameter (continuous variable), lower preoperative hemoglobin and eGFR, low volume center and OPN were significant predictive factors of overall surgical postoperative complications. At multivariable analysis ECOG score $\geq 1$ (OR 1.85; CI 1.20-2.85; $\mathrm{p}=0.01$ ), lower preoperative hemoglobin (OR 0.73; CI 0.63-0.84; $\mathrm{p}>0.0001)$, and open surgical approach (OR 2.79; CI $1.15-6.76 ; \mathrm{p}=0.02$ ) were confirmed as significant and independent predictive factors of overall surgical postoperative complications. At univariate analysis ECOG score $\geq 1$, OPN were significant predictive factors of Clavien 3 surgical and medical postoperative complications. At multivariable analysis ECOG score $\geq 1$ (OR 1.93; CI 0.95-4.03; $\mathrm{p}=0.04)$ and surgical approach $(\mathrm{p}=0.05)$ were confirmed to be independent factors of Clavien 3 surgical postoperative complications.

\section{Discussion}

The indications for PN have expanded, over the past decade, in comparison to radical nephrectomy (RN), because of comparable oncological and improved functional outcomes along with a better long-term survival due to reduced mortality for cardiovascular accidents. ${ }^{13}$ Conversely, the European Organization for Research and Treatment of Cancer (EORTC) trial 30904 demonstrates that PN seems to be significantly less effective than RN in terms of overall survival and several studies reported a significantly higher postoperative complication rates of $\mathrm{PN}$ in complex renal masses and/or comorbid patients. ${ }^{14}$

To date, the controversial opinions about the risk/benefit ratio of both PN and RN along with the clinical features of each patient often influenced the treatment decision for localized RCC.

The present analysis examined a contemporary, prospectively recorded, series of almost a thousand consecutive patients who underwent open, laparoscopic or robotic PN in 19 Italian centers and showed a pan view on the incidence and type of surgical and clinical complications that may occur after surgery.

Indeed, postoperative surgical complications represent the prominent concern of PN, as they have been descripted in up to $30 \%$ of historical series, with a major complication 
Table 3

Univariate and multivariate analysis for overall surgical postoperative complications.

\begin{tabular}{|c|c|c|c|c|c|c|c|}
\hline \multirow[t]{2}{*}{ Preoperative and surgical variables } & & \multicolumn{3}{|c|}{ Univariable analysis for surgical complications } & \multicolumn{3}{|c|}{$\begin{array}{l}\text { Multivariable analysis for surgical } \\
\text { complications }\end{array}$} \\
\hline & & No compl & Compl & $\mathrm{p}$ & OR & CI $95 \%$ & $\mathrm{p}$ \\
\hline \multirow[t]{2}{*}{ ECOG, n. (\%) } & 0 & $574(90.1 \%)$ & $63(9.9 \%)$ & $<0.0001$ & - & - & 0.01 \\
\hline & $\geq 1$ & $230(70.9 \%)$ & $58(20.1 \%)$ & & 1.85 & $1.20-2.85$ & \\
\hline Age, mean (SD) & & $61.7(12,6)$ & $63.1(13.2)$ & 0.19 & & & \\
\hline BMI, median (IQR) & & $26.0(24.1-28.4)$ & $26.2(24.1-28.4)$ & 0.53 & & & \\
\hline \multirow[t]{2}{*}{ Uncontrolled diabetes, n. (\%) } & No & $775(87.6 \%)$ & $110(12.4 \%)$ & 0.01 & - & - & 0.32 \\
\hline & Yes & $29(72.5 \%)$ & $11(27.5 \%)$ & & 1.55 & $0.66-3.65$ & \\
\hline \multirow[t]{2}{*}{ Uncontrolled hypertension, n. (\%) } & No & $707(87.5 \%)$ & $101(12.5 \%)$ & 0.17 & & & \\
\hline & Yes & $97(82.9 \%)$ & $20(17.1 \%)$ & & & & \\
\hline \multirow[t]{4}{*}{ Indication, n. (\%) } & & & & $<0.0001$ & & & 0.11 \\
\hline & Elective & $657(89.3 \%)$ & $79(10.7 \%)$ & & - & - & - \\
\hline & Relative & $104(81.9 \%)$ & $23(18.1 \%)$ & & 1,56 & $0.86-2.86$ & 0.18 \\
\hline & Absolute & $43(69.4 \%)$ & $19(30.6 \%)$ & & 2.05 & $1.05-4.01$ & 0.09 \\
\hline Clinical diameter, mean (SD) & & $3.1(1.3)$ & $3.5(1.3)$ & 0.01 & 1.13 & $0.98-1.31$ & 0.10 \\
\hline \multirow[t]{3}{*}{ Tumor site, n. (\%) } & Polar sup. & $227(87.0 \%)$ & $34(13.0 \%)$ & 0.67 & & & \\
\hline & Mesorenal & $322(85.9 \%)$ & $53(14.1 \%)$ & & & & \\
\hline & Polar inf. & $255(88.2 \%)$ & $34(11.8 \%)$ & & & & \\
\hline \multirow[t]{3}{*}{ Tumor growth pattern, n. (\%) } & $\geq 50 \%$ Exoph & $605(87.4 \%)$ & $87(12.6 \%)$ & 0.29 & & & \\
\hline & $<50 \%$ Exoph & $179(86.5 \%)$ & $28(13.5 \%)$ & & & & \\
\hline & Tot endoph & $20(76.9 \%)$ & $6(23.1 \%)$ & & & & \\
\hline Preoperative hemoglobin, mean (SD) & & $14.2(1.3)$ & $13.4(1.6)$ & $<0.0001$ & 0.73 & $0.63-0.84$ & $<0.0001$ \\
\hline Preoperative eGFR, median (IQR) & & $84.1(70.5-99.1)$ & $77.9(63.6-92.4)$ & 0.003 & 0.99 & $0.98-1.01$ & 0.74 \\
\hline \multirow[t]{2}{*}{ Center volume, n. (\%) } & High & $599(88.6 \%)$ & $77(11.4 \%)$ & 0.01 & - & - & 0.12 \\
\hline & Low & $205(82.3 \%)$ & $44(17.7 \%)$ & & 1,46 & $0.91-2.33$ & \\
\hline \multirow[t]{4}{*}{ Approach, n. (\%) } & & & & $<0.0001$ & & & 0.01 \\
\hline & Open & $431(82.6 \%)$ & $91(17.4 \%)$ & & 2,79 & $1.15-6.76$ & 0.02 \\
\hline & Laparoscopic & $262(91.6 \%)$ & $24(8.4 \%)$ & & 1,57 & $0.61-4.03$ & 0.39 \\
\hline & Robot-assisted & $111(94.9 \%)$ & $6(5.1 \%)$ & & - & - & - \\
\hline \multirow[t]{2}{*}{ Technique, n. \% } & SE & $327(87.4 \%)$ & $47(12.6 \%)$ & 0.70 & & & \\
\hline & $\mathrm{PN}$ & $477(86.6 \%)$ & $74(13.4 \%)$ & & & & \\
\hline Ischemia time (min), median (IQR) & & $16.0(13.0-21.0)$ & $16.5(12.0-21.0)$ & 0.12 & & & \\
\hline
\end{tabular}

rate of $3-6 \% .^{15}$ Bleeding is the most frequent and worrisome surgical complication, as shown by the large adoption of hemostatic agents in spite of a clear evidence of their usefulness. ${ }^{16}$

In the present study, overall and major surgical postoperative complications were reported in $13.1 \%$ and $3.5 \%$ of cases, respectively. The presence of comorbidity (analyzed as ECOG $\geq 1$ ), lower preoperative hemoglobin and the open surgical approach resulted as significant and independent predictive factors of the development of overall surgical postoperative complications. Conversely, age, BMI, uncontrolled hypertension and diabetes corrected pre-operatively, nephrometry parameters, surgical indication and surgical technique did not.

Conflicting results have been reported in the literature about the influence of comorbidities and performance status, variously recorded using the Charlson's comorbidity index (CCI), the age adjusted CCI, or the ECOG score, on surgical complications. Larcher et al. reported that $\mathrm{CCI}$ is a significant predicting factor (OR: 1.14, $\mathrm{p}<0.001$ ) of surgical complications, as well as age, tumor diameter, previous acute kidney injury, tumor size and open surgical approach in over 1962 patients treated for T1a
RCC. ${ }^{15}$ Conversely, in other studies comorbidity, reported as CCI, age adjusted CCI and the American Society of Anesthesiologists (ASA) physical status classification system, was not reported as significant predictive factors of complications. $^{4,7,17}$

The evaluation of performance status in the present series showed that patients with ECOG $\geq 1$ have a 1.85 and a 1.93-fold significant risk of development of overall and Clavien 3 surgical complications, respectively. Moreover, higher level of serum hemoglobin revealed to be significant protective factor with occurrence of overall surgical complications. These results may confirm the indication of performing $\mathrm{RN}$ in comorbid and weak patients to reduce the risk of complications, but, on the other hand, PN can be justified by the theoretical benefit of avoiding longterm decrease of renal function, that in this cohort of patients may be even more important in order to increase overall survival.

RAPN might represent a viable alternative to OPN in this subgroup of patients for its protective effect from complications. Indeed, in our series, we had the opportunity to evaluate together the potential effects on complications of OPN, LPN and RAPN. OPN was performed in all of the 
Table 4

Univariate and multivariate analysis for Clavien 3 surgical and medical postoperative complications.

\begin{tabular}{|c|c|c|c|c|c|c|c|}
\hline \multirow[t]{2}{*}{ Preoperative and surgical variables } & & \multicolumn{3}{|c|}{$\begin{array}{l}\text { Univariable analysis for surgical and medical } \\
\text { Clavien } 3 \text { complications }\end{array}$} & \multicolumn{3}{|c|}{$\begin{array}{l}\text { Multivariable analysis for Clav } 3 \\
\text { complications }\end{array}$} \\
\hline & & No compl & Compl & $\mathrm{p}$ & OR & CI $95 \%$ & $\mathrm{p}$ \\
\hline \multirow[t]{2}{*}{ ECOG, n. (\%) } & 0 & $621(97.5 \%)$ & $16(2.5 \%)$ & 0.03 & - & - & 0.04 \\
\hline & $\geq 1$ & $269(93.4 \%)$ & $19(6.6 \%)$ & & 1.93 & $0.95-4.03$ & \\
\hline Age, mean (SD) & & $61.8(12.6)$ & $64.2(14.6)$ & 0.36 & & & \\
\hline BMI, median (IQR) & & $26.0(24.1-28.4)$ & $26.8(24.1-29.8)$ & 0.28 & & & \\
\hline \multirow[t]{2}{*}{ Uncontrolled diabetes, n. (\%) } & No & $852(96.2 \%)$ & $34(3.8 \%)$ & 0.73 & & & \\
\hline & Yes & $39(97.5 \%)$ & $1(2.5 \%)$ & & & & \\
\hline \multirow[t]{2}{*}{ Uncontrolled hypertension, n. (\%) } & No & $777(96.2 \%)$ & $32(3.9 \%)$ & 0.57 & & & \\
\hline & Yes & $114(97.4 \%)$ & $3(2.6 \%)$ & & & & \\
\hline \multirow[t]{3}{*}{ Indication, n. (\%) } & Elective & $712(96.5 \%)$ & $26(3.5 \%)$ & 0.36 & & & \\
\hline & Relative & $123(96.9 \%)$ & $4(3.1 \%)$ & & & & \\
\hline & Absolute & $57(91.9 \%)$ & $5(8.1 \%)$ & & & & \\
\hline Clinical diameter, mean (SD) & & $3.2(1.3)$ & $3.3(1.3)$ & 0.51 & & & \\
\hline \multirow{3}{*}{ Tumor site, n. (\%) } & Polar sup. & $253(97.3 \%)$ & $8(2.7 \%)$ & 0.34 & & & \\
\hline & Mesorenal & $357(95.5 \%)$ & $18(4.5 \%)$ & & & & \\
\hline & Polar inf. & $280(97.2 \%)$ & $9(2.8 \%)$ & & & & \\
\hline \multirow[t]{3}{*}{ Tumor growth pattern, n. (\%) } & $\geq 50 \%$ Exo & $253(92.7 \%)$ & $20(7.3 \%)$ & 0.10 & & & \\
\hline & $<50 \%$ Exo & $194(93.7 \%)$ & $13(6.3 \%)$ & & & & \\
\hline & Tot endo & $24(92.3 \%)$ & $2(7.7 \%)$ & & & & \\
\hline Preoperative hemoglobin, mean (SD) & & $14.1(1.4)$ & $13.8(1.2)$ & 0.24 & & & \\
\hline Preoperative eGFR, median (IQR) & & $83.1(69.9-97.5)$ & $76.8(69.3-88.7)$ & 0.20 & & & \\
\hline \multirow[t]{2}{*}{ Centre volume, n. (\%) } & High & $655(96.6 \%)$ & $23(3.4 \%)$ & & & & \\
\hline & Low & $235(94.0 \%)$ & $15(6.0 \%)$ & & & & \\
\hline \multirow[t]{4}{*}{ Approach, n. (\%) } & & & & 0.03 & & & 0.05 \\
\hline & Open & $495(94.3 \%)$ & $30(5.7 \%)$ & & 5,65 & $1.79-21.91$ & 0.07 \\
\hline & Laparoscopic & $279(97.9 \%)$ & $7(2.1 \%)$ & & 2,41 & $0.98-12.37$ & 0.41 \\
\hline & Robot-assisted & $116(99.1 \%)$ & $1(0.9 \%)$ & & - & - & - \\
\hline \multirow[t]{2}{*}{ Technique, n. $\%$} & Simple enucleation & $355(94.4 \%)$ & $21(5.6 \%)$ & 0.13 & & & \\
\hline & Standard PN & $535(96.9 \%)$ & $17(3.1 \%)$ & & & & \\
\hline
\end{tabular}

nineteen centers. LPN was available in eleven centers and it was used since the beginning of the study, while RAPN was available in five high volume centers only in the last two years of data collection. ${ }^{8}$ All surgeons were skilled in each of the three approaches performed: the choice among the approaches was primarily based on the availability of the technologies in the centres involved, but also on the surgeons' skills and experience. The different preoperative features, as comorbidity and the anatomical features of the tumors between the three approaches, might represent a possible bias in the analyses. Therefore, we performed accurate statistical analyses including important patients' and tumors' related factors that confirmed that the open surgical approach was strongly and independently associated with the development of postoperative surgical complications (Tables 3 and 4). In detail, OPN was associated with a nearly three-fold risk of overall postoperative surgical complications in comparison with RAPN and surgical approach was a significant and independent predicting factor of major complications (Clavien 3 surgical and medical complications). These results agree with a large retrospective study by Ghani et al., which analyzed the postoperative outcomes in patients submitted to $\mathrm{PN}$ in US from 2008 to 2012 and showed that RAPN and LPN were significantly associated with a lower risk of overall postoperative complications and transfusion rate compared to OPN. ${ }^{18}$ A possible explanations being the benefits of minimally invasive surgery in addition to the improved dexterity and vision of robotic system that makes open surgery actions replicable and more precise with a robotic approach.

The surgical technique adopted, has been reported to have a potential effect on the development of surgical postoperative complications for the protective role of SE with a decreased rate of entry into the renal sinus and of calyceal injuries, as long as a reduced need for tumor bed suturing and a reduced warm ischemia time. ${ }^{10,19}$

On the contrary, the present study did not show any protective role of SE on surgical postoperative complications. Several explanations can be provided: first, the surgical technique was not recorded using the SIB margin score, a newly developed system that aims to standardize the reporting of surgical techniques, ${ }^{20}$ while all data were registered according to the surgeon-intention. Furthermore, the advantages of SE could be more evident in a subgroup of patients with large endophytic tumors instead of in the entire series that included also a substantial number of cortical lesions where the removal of a subtle rim of normal parenchyma may not injury main parenchymal vessels or calyceal system. $^{3}$ 
Several studies demonstrated that nephrometry scores might significantly predict the risk of complications. ${ }^{7,4,21}$ However, Desantis et al. suggested that some clinical tumor features included in the nephrometry scores, such as clinical diameter and endophytic growth pattern, seem more predictive of complications than others do. ${ }^{22}$ In the present study, nephrometry scores were not reported as they had been introduced in literature after the generation of this prospective database (2008). Nevertheless, all nephrometry tumor features, such as clinical diameter, growth pattern, polar site, localization including hilar location and side, were descripted and none of these significantly predicts surgical complications. Moreover, we performed a uni- and multi-variable analysis with a modified PADUA score, which included all anatomical features but urinary calyceal system compression or invasion. This score did not significantly influence the incidence of overall surgical and major surgical and medical postoperative complications both as a continuous and as a divided risk class groups while the other variables did not change their significance at multivariable analysis (Results not showed).

This study is not devoid of limitations: cases were done by a wide set of surgeons in different centers: all surgeons were skilled in the approach performed. However, this might have increased the external reproducibility of the data with respect to a single-center or single-surgeon setting. As above mentioned, nephrometry scores were not reported. Despite these limitations, this study offers a wide report of perioperative features from a large multicenter prospectively recorded dataset of PN, performed either with open, laparoscopic and robot-assisted approach. Finally, the report of complications fulfilled the EAU standardized quality criteria.

In conclusion, the presence of comorbidities have to be weighted in the preoperative assessment of patients candidate to PN, as it was found to be significantly associated to overall and major surgical complications. Moreover, minimally invasive approach should be preferred, whenever possible, to avoid the risk of surgical complications.

\section{Conflict of interest statement}

All authors disclose any financial and personal relationships with other people or organizations that could inappropriately influence their work.

No study sponsor has been involved.

\section{References}

1. Znaor A, Lortet-Tieulent J, Laversanne M. International variations and trends in renal cell carcinoma incidence and mortality. Eur Urol 2015 Mar;67(3):519-30. http://dx.doi.org/10.1016/j.eururo.2014.10.002 Epub 2014 Oct 16. Review.

2. Ljungberg B, Bensalah K, Canfield S, et al. EAU guidelines on renal cell carcinoma: 2014 update. Eur Urol 2015 May;67(5):913-24. http:// dx.doi.org/10.1016/j.eururo.2015.01.005 Epub 2015 Jan 21.
3. Serni S, Vittori G, Frizzi J, et al. Simple enucleation for the treatment of highly complex renal tumors: perioperative, functional and oncological results. Eur J Surg Oncol 2015 Jul;41(7):934-40. http:// dx.doi.org/10.1016/j.ejso.2015.02.019.

4. Tanagho YS, Kaouk JH, allaf ME, et al. Perioperative complications of robot-assisted partial nephrectomy: analysis of 886 patients at 5 United States centers. Urology 2013 Mar;81(3):573-9. http:// dx.doi.org/10.1016/j.urology.2012.10.067.

5. Hadjipavlou M, Khan F, Fowler S. Partial vs radical nephrectomy for T1 renal tumours: an analysis from the British Association of Urological Surgeons Nephrectomy Audit. BJU Int 2015 Mar 6. http:// dx.doi.org/10.1111/bju.13114.

6. Dindo D, Demartines N, Clavien PA. Classification of surgical complications. A new proposal with evalutation in a cohort of 6336 patients and results of a survey. Ann Surg 2004;240:205-13.

7. Ficarra V, Novara G, Secco S, et al. Preoperative aspects and dimensions used for an anatomical (PADUA) classification of renal tumours in patients who are candidates for nephron-sparing surgery. Eur Urol 2009 Nov;56(5):786-93. http://dx.doi.org/10.1016/j.eururo.2009.07.040 Epub 2009 Aug 4.

8. Schiavina R, Mari A, Antonelli A. A snapshot of nephron-sparing surgery in Italy: a prospective, multicenter report on clinical and perioperative outcomes (the RECORd 1 project). Eur J Surg Oncol 2015 Mar;41(3):346-52. http://dx.doi.org/10.1016/j.ejso.2014.12.001 Epub 2014 Dec 27.

9. Oken MM, Creech RH, Tormey DC, et al. Toxicity and response criteria of the Eastern Cooperative Oncology Group. Am J Clin Oncol 1982;5:649-55.

10. Minervini A, Ficarra V, Rocco F, et al. Simple enucleation is equivalent to traditional partial nephrectomy for renal cell carcinoma: results of a nonrandomized, retrospective, comparative study. J Urol 2011 May;185(5):1604.

11. Martin 2nd RC, Brennan MF, Jaques DP. Quality of complication reporting in the surgical literature. Ann Surg 2002;235:803-13.

12. Mitropoulos D, Artibani W, Biyani CS, et al. Quality assessment of partial nephrectomy complications reporting using EAU standardised quality criteria. Eur Urol 2014;66(3):522-6.

13. Capitanio U, Terrone C, Antonelli A, et al. Nephron-sparing techniques independently decrease the risk of cardiovascular events relative to radical nephrectomy in patients with a T1a-T1b renal mass and normal preoperative renal function. Eur Urol 2014 Oct 2. http://dx.doi.org/10.1016/j.eururo.2014.09.027 pii: S0302-2838(14) 00964-6.

14. Van Poppel H, Da Pozzo L, Albrecht W, et al. A prospective, randomised EORTC intergroup phase 3 study comparing the oncologic outcome of elective nephron-sparing surgery and radical nephrectomy for low-stage renal cell carcinoma. Eur Urol 2011 Apr;59(4):543-52. http://dx.doi.org/10.1016/j.eururo.2010.12.013 Epub 2010 Dec 22.

15. Larcher A, Fossati N, Tian Z, et al. Prediction of complications following partial nephrectomy: implications for ablative techniques candidates. Eur Urol 2015 Jul 20. http://dx.doi.org/10.1016/j.eururo.2015.07.003 pii: S0302-2838(15)00607-7.

16. Antonelli A, Minervini A, Mari A, et al. TriMatch comparison of the efficacy of FloSeal versus TachoSil versus no hemostatic agents for partial nephrectomy: results from a large multicenter dataset. Int $J$ Urol 2015;22:47-52.

17. Hakimi AA, Rajpathak S, Chery L, et al. Renal insufficiency is an independent risk factor for complications after partial nephrectomy. J Urol 2010;183:43-7.

18. Ghani KR, Sukumar S, Sammon JD, et al. Practice patterns and outcomes of open and minimally invasive partial nephrectomy since the introduction of robotic partial nephrectomy: results from the nationwide inpatient sample. J Urol 2014 Apr;191(4):907-12. http:// dx.doi.org/10.1016/j.juro.2013.10.099 Epub 2013 Oct 29.

19. Mukkamala A, Allam CL, Ellison JS, et al. Tumor enucleation vs sharp excision in minimally invasive partial nephrectomy: technical benefit without impact on functional or oncologic outcomes. Urology 
$2014 \quad$ Jun;83(6):1294-9. http://dx.doi.org/10.1016/j.urology.2014.02.007 Epub 2014 Apr 6.

20. Minervini A, Carini M, Uzzo RG, et al. Standardized reporting of resection technique during nephron-sparing surgery: the surfaceintermediate-base margin score. Eur Urol 2014 Nov;66(5):803-5. http://dx.doi.org/10.1016/j.eururo.2014.06.002 Epub 2014 Jun 18.

21. Serni S, Vittori G, Masieri L, et al. Robotic vs open simple enucleation for the treatment of T1a-T1b renal cell carcinoma: a single center matched-pair comparison. Urology 2014 Feb;83(2):331-7. http:// dx.doi.org/10.1016/j.urology.2013.08.080 Epub 2013 Nov 22.

22. Desantis D, Lavallée LT, Witiuk K, et al. The association between renal tumour scoring system components and complications of partial nephrectomy. Can Urol Assoc J 2015 Jan-Feb;9(1-2):39-45. http:// dx.doi.org/10.5489/cuaj.2303. 